\title{
Construction of novel promoters based on the characteristics of drought stress specific cis-regulatory element
}

\author{
Kihwan Kim ${ }^{1} \cdot$ Byeonggyu Kim² ${ }^{2}$ Juhyung Shin ${ }^{2} \cdot$ Won-Chan Kim ${ }^{1,2}$ (iD \\ 가뭄 스트레스 특이적인 cis-regulatory element의 특성을 기반으로 한 \\ 신규 프로모터 구축
}

김기환 ${ }^{1} \cdot$ 김병 $^{2} \cdot$ 신주형 $^{2} \cdot$ 김원찬 $^{1,2}$

Received: 9 November 2020 / Accepted: 31 December 2020 / Published Online: 31 March 2021

(C) The Korean Society for Applied Biological Chemistry 2021

\begin{abstract}
Droughts are one of the abiotic stresses that hinders the growth and productivity of crop plants. Coping with abiotic stress is necessary to understand the molecular regulatory networks that makes plants respond to adverse environmental conditions. In our experiment to find a combination that can cope with abiotic stress (respond to drought), we screened 5 stressinducible promoters that are expressed only under stress conditions. This founded 36 cis-elements in stress-inducible promoters. With the result we designed 2 synthetic promoters (BL1, BL2) for fine-controlled regulation by assembling ciselements from the native promoters, which are expressed only under stress caused by droughts. Analysis of the transgenic plant (BL1-GUS, BL2-GUS) showed that the synthetic promoters increased the expression of $\beta$-glucuronidase (GUS) in transgenic plants under desiccation. Also in the transient activation assay demonstrated that synthetic promoters induced the cotransformation of effector DREB1A and DREB2C. These results
\end{abstract}

\section{Won-Chan Kim $(\bowtie)$}

E-mail: kwc@knu.ac.kr

${ }^{1}$ Department of Applied Biosciences, Kyungpook National University, Daegu 41566, Republic of Korea

${ }^{2}$ Department of Integrative Biology, Kyungpook National University, Daegu 41566, Republic of Korea

This is an Open Access article distributed under the terms of the Creative Commons Attribution Non-Commercial License (http://creativecommons. org/licenses/by-nc/3.0/) which permits unrestricted non-commercial use, distribution, and reproduction in any medium, provided the original work is properly cited. expect that the synthetic promoter with a combination of droughtspecific elements can be used to respond to various abiotic stress and is resistant to stress without causing growth retardation.

Keywords Cis-regulatory element · Drought $\cdot$ Fine-controlled regulation $\cdot$ Synthetic promoter

서 론

식물은 가뭄, 염분, 고온 및 저온 또는 이산화탄소와 같은 비 생물학적 스트레스에 빈번히 노출되고 있다. 이러한 비 생물학 적 스트레스는 전 세계적으로 농작물 손실의 주요 원인이며, 주 요 농작물에서 평균 수확량 손실의 $50 \%$ 이상이 비 생물학적 스트레스에 의해 발생하고 있다[1]. 비 생물학적 스트레스 중 가뭄에 의한 환경 스트레스는 다양한 생리적 발달 변화를 일으 키며, 식물의 성장, 발달 등의 저해로 많은 문제를 일으키는 주 요한 환경 요인이다. 옥수수와 같은 식용 작물들은 가뭄 스트 레스에 민감하게 반응하며, 작물의 품질 저하 및 생산성 저하 등의 부작용이 가뭄 스트레스에 의해 나타나고 있다. 이러한 문 제를 해결하고자 가뭄 스트레스에 대한 내성이 향상된 작물을 개발하려는 시도가 많이 이루어져 왔다. 식물의 모든 조직에서 높은 수준으로 유전자를 발현시키는 $35 \mathrm{~S}$ cauliflower mosaic virus (CaMV) 프로모터를 이용한 여러 후보 유전자에 관한 연 구가 축적되어왔으며, 모델 식물을 이용한 이들 후보 유전자의 과발현을 통해 의미 있는 연구 결과들이 도출되어오고 있다[24]. 하지만, $\mathrm{CaMV} 35 \mathrm{~S}$ 프로모터의 특징인 항상성으로 인해 정 상적인 생육조건에서도 유전자의 발현이 강하게 유도되어 식물 
생육에 부정적인 영향을 미치는 문제점의 해결은 여전히 부족 한 실정이다[5,6].

효율적인 스트레스 내성 형질전환 작물의 개발을 위한 전략 중 하나는, 유전자의 발현을 조절하는 것이다. 전사 수준에서 유전자 발현을 조절하는 프로모터는 전사 시작 부위의 상류에 위치하는 cis-regulatory element에 의해 조절된다[7,8]. Cisregulatory element는 비 생물학적 스트레스를 포함한 다양한 생 리적, 생화학적 및 유전자 조절 네트워크의 조절에 관여하는 중 요한 요소이다. 실제로, 효모 프로모터의 cis-regulatory element 의 조합을 통해 유전자 발현을 조절할 수 있다는 보고가 있다 [9].

일부 식물 프로모터는 비 생물학적 스트레스에 활성화되는 것 으로 알려져 있으며, 이들 프로모터는 ABA-responsive element (ABRE)와 dehydration-responsive element/C repeat (DRE/ $\mathrm{CRT}$ ) 등과 같은 비 생물학적 스트레스에 주요 cis-regulatory element를 가지고 있다[10-17]. ABRE (PyACGTGGC)는 ABAdependent regulatory system을 통해 하위 유전자의 발현을 조 절한다[18]. DRE/CRT (GCCGAC)는 ABA-independent regulatory system을 통해 유전자 발현을 조절한다[19,20]. 이 외에도 $\mathrm{MYB}$ (C/TAACNA/G), MYC (CANNTG), LTRE (CCGAC)와 같은 cis-regulatory element도 삼투 스트레스 및 $\mathrm{ABA}$ 에 대한 반응으 로 유전자 발현을 조절한다[21,22].

본 연구에서는 가뭄 스트레스에 특이적인 cis-regulatory element의 새로운 조합을 통한 합성프로모터를 구축하고 다양한 비 생물학적 스트레스에 반응하여 유전자 발현을 조절할 수 있 음을 확인하였다. 이는 정상적인 생육조건에서는 유전자 발현이 되지 않고, 비 생물학적 스트레스 조건에서만 특이적으로 유전 자 발현이 유도되어 효율적인 스트레스 내성 작물 개발에 도움 이 될 것으로 생각된다.

\section{재료 및 방법}

\section{식물재료 및 식물성장조건}

애기장대(Arabidopsis thaliana)는 야생형(Col-0)을 실험에 사용 하였다. 애기장대의 종자는 $70 \%$ ethanol을 이용하여 5 분간 소 독 후 종자 소독제( $25 \%$ 표백제 및 $0.01 \%$ Triton X-100)를 이 용하여 10 분간 표면을 살균하여 사용하였다. 표면 멸균된 종자 는 증류수로 헹군 뒤 $0.5 \times$ Murashige and Skoog 한천 배지 (0.002\% MS, $6 \mathrm{mM}$ MES, $1 \%$ Sucrose, 0.6\% Agar, pH5.7) 에 파종하여 춘화 처리 후 생육시키며 사용하였다. 생육조건은 생장상에서 장일조건 $\left(16\right.$ 시간 명 처리/8시간 암 처리, $\left.23{ }^{\circ} \mathrm{C}\right)$ 으 로 생육시켰다.

\section{가뭄 스트레스 처리 및 가뭄 스트레스 해소 조건}

가뭄 스트레스에 특이적으로 발현이 유도되는 유전자를 선별하 기 위한 가뭄 스트레스 처리 실험에서는 8 일간 생육시킨 애기 장대를 시간대별로 자연 건조하여 사용하였다[10]. 합성프로모 터의 성능을 검증하기 위한 가뭄 스트레스 처리 실험은 Polyethylene glycol (Sigma Aldrich, St. Louis, MO, USA)가 첨가된 $-0.77 \mathrm{MPa} 0.5 \times$ Murashige and Skoog 한천 배지에서 3일간 생육하여 사용하였다[23]. 가뭄 스트레스 해소는 가뭄 스 트레스 처리된 애기장대를 새로운 $0.5 \times$ Murashige and Skoog 한천 배지에 옮겨 심어 3일간 생육시켜 사용하였다.

\section{RNA 추출 및 RT-PCR}

Total RNA의 추출은 TRIzol reagent (Invitrogen, CA, Carlsbad, USA)를 사용하여 가뭄 스트레스 처리된 애기장대 및 대조군의 잎과 뿌리을 추출하였다. 추출된 total RNA는 Superscript II reverse transcriptase (Invitrogen)를 사용하여 cDNA로 역전시켰

Table 1 List of primers used for RT-PCR amplification

\begin{tabular}{|c|c|c|c|c|}
\hline Gene name & AGI Locus Identifier & Primer sequence $\left(5^{\prime} \rightarrow 3^{\prime}\right)$ & $\operatorname{Tm}\left({ }^{\circ} \mathrm{C}\right)$ & Amplicon length (bp) \\
\hline P5CS1 & AT2G39800 & $\begin{array}{l}\text { F: GGACCAAGGGCAAGTAAGATACTG } \\
\text { R: CCGACTGGACCACGAGCATGG }\end{array}$ & $\begin{array}{l}59.9 \\
64.4\end{array}$ & 314 \\
\hline LTI30 & AT3G50970 & $\begin{array}{l}\text { F: GGTCATCATGGTGCTACTGGTAC } \\
\text { R: GATGACCTGGCAGTTGCTCTTTAATC }\end{array}$ & $\begin{array}{l}59.8 \\
61.3\end{array}$ & 313 \\
\hline ATHB-7 & AT2G46680 & $\begin{array}{l}\text { F: GGTTCAATTAGCTAGAGAGCTAGGG } \\
\text { R: CGGTTCTCTTCGTTTTCTGATTCATG }\end{array}$ & $\begin{array}{l}59.3 \\
59.9\end{array}$ & 306 \\
\hline $\mathrm{PP} 2 \mathrm{C}$ & AT1G07430 & $\begin{array}{l}\text { F: GCGGTGACTCAAGAGCAGTTCTTTG } \\
\text { R: CATCGTACACGCTGCCTCGTTC }\end{array}$ & $\begin{array}{l}63.5 \\
63.1\end{array}$ & 308 \\
\hline LEA4-5 & AT5G06760 & $\begin{array}{l}\text { F: GCAGTCGATGAAAGAAACAGCTTCG } \\
\text { R: GAGCCGACATCTGATGTGTCCC }\end{array}$ & $\begin{array}{l}62.1 \\
62.0\end{array}$ & 308 \\
\hline ATGOLS2 & AT1G56600 & $\begin{array}{l}\text { F: CGGTATGTTCGTTTACGAGCCTAAC } \\
\text { R: CCCACCATTTCTTGACCAGCATC }\end{array}$ & $\begin{array}{l}61.0 \\
61.0\end{array}$ & 308 \\
\hline ERF53 & AT2G20880 & $\begin{array}{l}\text { F: GGGTTGCCGAGATCCGTAAGC } \\
\text { R: GCATTGAACCATGCCTCAGCC }\end{array}$ & $\begin{array}{l}62.4 \\
61.5\end{array}$ & 304 \\
\hline RD29A & AT5G52310 & $\begin{array}{l}\text { F: GCTTTCTGGAACAGAGGATGTAACG } \\
\text { R: CTCTTTGAATTCTTTGCTTCTCGTCG }\end{array}$ & $\begin{array}{l}60.9 \\
60.1\end{array}$ & 307 \\
\hline ACTIN8 & AT1G49240 & $\begin{array}{l}\text { F: CATCATTTGTTGGAATGGAA } \\
\text { R: ATACTCTGCCTTAGAGATCCACAT }\end{array}$ & $\begin{array}{l}51.0 \\
57.6\end{array}$ & 296 \\
\hline
\end{tabular}


다. RT-PCR은 생성된 $\mathrm{cDNA}$ 를 주형으로 사용하여 수행되었으 며, 증폭된 DNA 단편을 $1 \%$ Agarose (Invitrogen)에서 분리하 고 ethidium bromide (BioBasic, Toronto, CAN)로 염색하여 확인하였다. RT-PCR에 사용된 프라이머는 Table 1에 별도로 표 기하였다.

\section{cis-regulatory element 분석}

TAIR (https:/www.arabidopsis.org)를 활용하여 CDS (coding sequence) 의 상위 $2 \mathrm{~kb}$ 프로모터 영역을 획득하였으며, PlantPAN 3.0 (https://www.plantpan.itps.ncku.edu.tw)를 사용하여 프로모터 영 역에 존재하는 cis-regulatory element를 확인하였다[24,25].

\section{합성프로모터 제작 및 식물 형질전환}

cis-regulatory element가 조합된 합성프로모터는 Integrated DNA Technology를 통해 합성을 진행하였다. 제작된 합성프로 모터들은 SpeI과 $B a m H I$ 의 제한효소를 통해 pCB308 벡터[26] 에 삽입하여 재조합 벡터를 제작하였다. 재조합 벡터들은 아그 로박테리움(GV3101)을 이용한 floral dip method [27]를 통해 실시하였다.

\section{조직 GUS 염색 및 정량적 GUS 활성 분석}

조직 $\beta$-glucuronidase (GUS) 염색은 가뭄 스트레스 처리된 애 기장대와 대조군을 함께 5-bromo-4-chloro-3-indolyl glucuronide (Gold Biotechnolgy, St. Louis, MO, USA)를 함유하는 GUS 반응 혼합물에 24시간 침지 후, $70 \%$ ethanol을 사용하여 엽록 소를 제거하여 확인하였다[28]. 엽록소가 제거된 애기장대는 Leica사(Wetzlar, DEU)의 EZ4E 모델 현미경을 사용하여 관찰 하였다. GUS 단백질의 활성을 측정은 4-Methylumbelliferyl $\beta$ D-galactopyranoside의 분해 산물인 4-methylumbelliferone을 Specta Max Gemini XS (Molecular Devices, Sunnyvale, CA, USA)로 측정하였다[29]. 단백질의 농도는 Bradford reagent (Bio-Rad, CA, Hercules, USA)를 통해 정량 분석하였다[30]. GUS 단백질의 활성은 밀리그램 단백질 당 분당 피코 몰 4methylumbelliferone으로 표현되었다.

\section{식물 원형질체 분리 및 Transient activity assay}

합성프로모터의 성능을 확인하기 위하여 애기장대의 잎으로부 터 원형질체를 추출하고[31] effector와 reporter 벡터는 pTrGUS 벡터[32]를 제작하여 실험하였다. Effector 벡터의 구축을 위하 여는 DREB1A (At4g25480) 및 DREB2C (At2g40340)의 cDNA 를 $\mathrm{CaMV} 35 \mathrm{~S}$ 프로모터 하류에 삽입시켰고, reporter 벡터는 합성프로모터를 GUS 리포터 유전자 상류에 삽입하여 제작하였 다. 이렇게 제작된 effector 및 reporter 벡터는 원형질체 내부로 도입시켜 실험하였다[33]. Effector와 reporter 벡터를 동시에 형 질전환시킨 원형질체는 상온에서 12 시간 반응시킨 후 생성된 GUS 단백질을 추출하고, 이를 이용한 반응의 분해 산물인 4methylumbelliferone을 Specta Max Gemini XS (Molecular Devices)로 정량하였다. Effector 및 reporter의 형질전환 수율은 Neuraminidase (NAN)을 형질전환을 통해 보정하였다[34].

\section{통계 분석}

모든 실험 결과는 3 회 반복으로 시행하여 평균 \pm 표준편차 (standard deviation, $\mathrm{SD}$ )를 사용해 표기하였다. 통계 분석은 Student's t-test를 사용하여 $p$ 값이 0.05 미만일 때 통계적으로 유의한 것으로 간주하였다.

\section{결과 및 고찰}

\section{가뭄 스트레스에 반웅하는 프로모터 선별}

애기장대 내에서 가뭄 스트레스에 특이적으로 반응하는 유전자 를 선별하기 위해 기존의 논문들을 통해 가뭄 스트레스 내성 유전자들을 선정하였다(Table 2). 선정된 가뭄 스트레스 내성 유 전자들은 시간대별로 자연 건조를 통해 가뭄 스트레스 처리된 애기장대 및 가뭄 스트레스 해소된 애기장대 내의 mRNA의 양 을 RT-PCR을 통해 측정하였다(Fig. 1). 그 결과, 애기장대의 잎 과 뿌리에서 가뭄 스트레스가 증가할수록 모든 가뭄 스트레스 내성 유전자의 mRNA의 양이 증가함을 확인할 수 있었다. 하 지만 자연 건조 후 2 시간과 4 시간 뒤의 애기장대를 새로운 배

Table 2 List of drought stress resistance gene

\begin{tabular}{clcc}
\hline \hline AGI Locus Identifier & \multicolumn{1}{c}{ Gene name } & Biological/molecular function & Reference \\
\hline \multirow{2}{*}{ AT2G39800 } & ATP5CS, DELTA1-PYRROLINE-5-CARBOXYLATE SYNTHASE 1, & ABA, Cold, Osmotic, Salinity & {$[12]$} \\
& P5CS1 & Cold, Drought, & {$[17]$} \\
\hline AT3G50970 & LOW TEMPERATURE-INDUCED 30, LTI30, XERO2 & Drought, ABA & {$[11]$} \\
\hline \multirow{2}{*}{ AT2G46680 } & $\begin{array}{l}\text { ARABIDOPSIS THALIANA HOMEOBOX 7, ATHB-7, ATHB7, HB-7, } \\
\text { HOMEOBOX 7 }\end{array}$ & ABA signaling, Drought & {$[16]$} \\
\hline \multirow{2}{*}{ AT1G07430 } & $\begin{array}{l}\text { AIP1, AKT1 INTERACTING PROTEIN PHOSPHATASE 1, ATAIP1, } \\
\text { HAI2, HIGHLY ABA-INDUCED PP2C GENE 2, HON }\end{array}$ & Drought & Drought \\
\hline AT5G06760 & ATLEA4-5, LATE EMBRYOGENESIS ABUNDANT 4-5, LEA4-5 & Drought, salt, osmotic stress, \\
AT1G56600 & ATGOLS2, GALACTIONL SYNTHASE 2, GOLS2 & {$[15]$} \\
\hline \multirow{2}{*}{ AT2G20880 } & ATERF53, ERF DOMAIN 53, ERF53 & ABA, Salt, Drought & {$[10]$} \\
\hline \multirow{2}{*}{ AT5G52310 } & $\begin{array}{l}\text { COLD REGULATED 78, COR78, LOW-TEMPERATURE-INDUCED 78, } \\
\text { LTI140, LTI78, RD29A, RESPONSIVE TO DESICCATION 29A }\end{array}$ \\
\hline
\end{tabular}


(A)

$$
\text { Desiccation Re-watering }
$$

$$
\text { Oh } 0.5 \mathrm{~h} \quad 1 \mathrm{~h} \quad 2 \mathrm{~h} \quad 4 \mathrm{~h} \quad 2 \mathrm{~h} \quad 4 \mathrm{~h}
$$

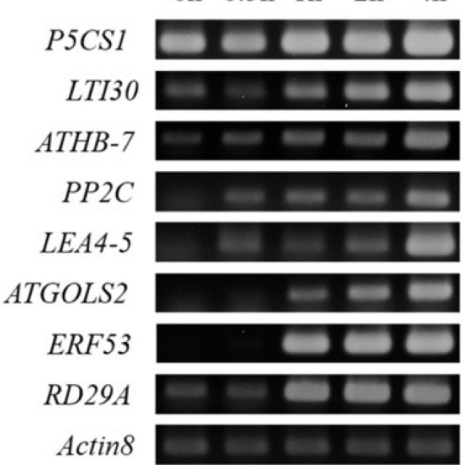

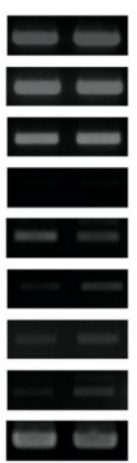

(B)

Desiccation

Re-watering

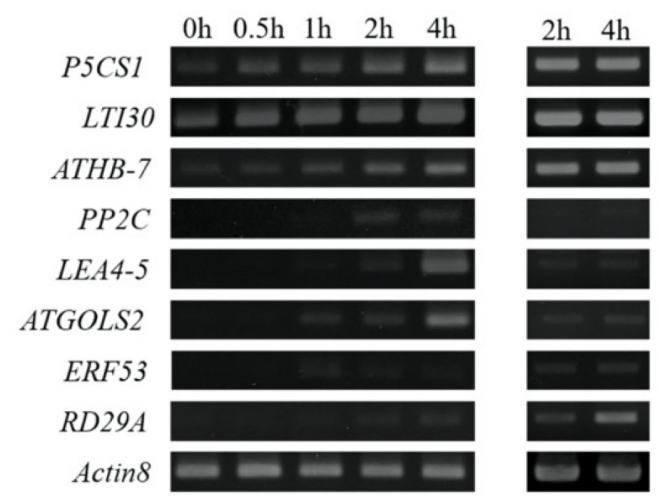

Fig. 1 Reverse-transcriptase PCR showing the expression of genes responsive to drought stress. Total RNA was extracted from the leaves (A) and/or roots (B) of Arabidopsis thaliana Col-0. A. thaliana Col-0 was dried for 0, 0.5, 1, 2, 4 hours in clean bench and the samples dried for 2, $4 \mathrm{~h}$ were transferred to fresh media for re-watering and grown for 2 days. The RT-PCR product of Actin 8 was used as a control

(A)

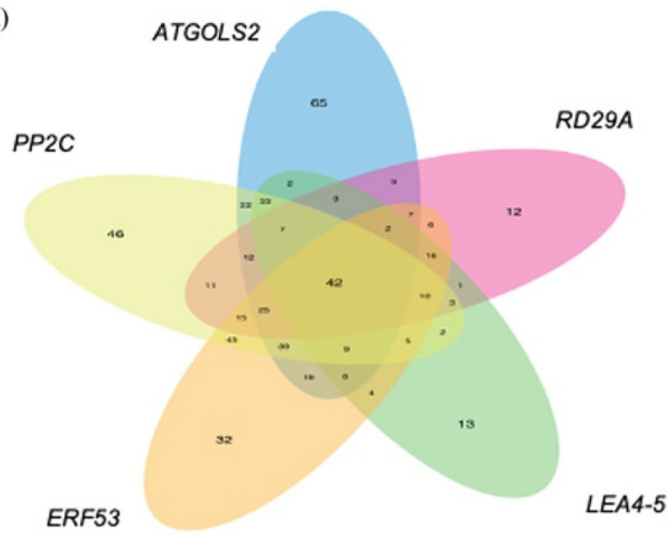

(B)

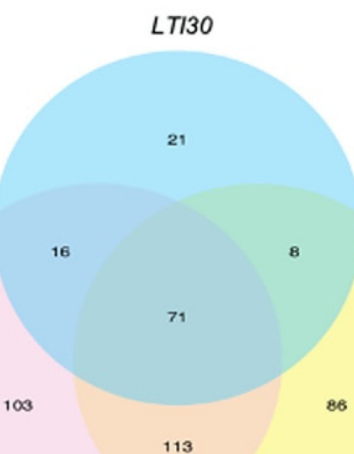

ATHB-7
P5CS1

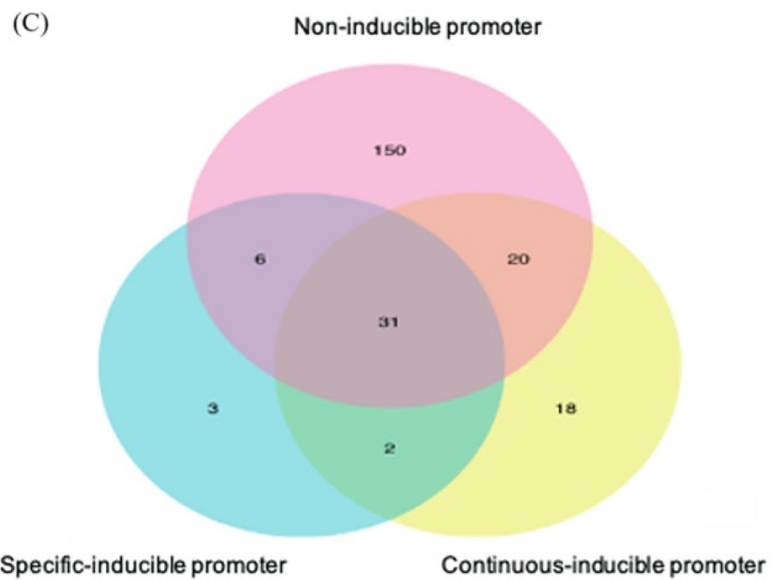

Fig. 2 Venn diagram representing prediction transcription binding site of stress-inducible promoters. The numbers in the Venn diagram indicate the number of TF-matrix-ID or TF-motif-sequence found to be shared among the indicated promoters. Specific-inducible promoter involved PP2C, LEA45, ATGOLS2, ERF53, RD29A. Continuous-inducible promoter involved P5CS1, LTI30, ATHB-7. Non-inducible promoter involved promoter that does not response to drought stress 

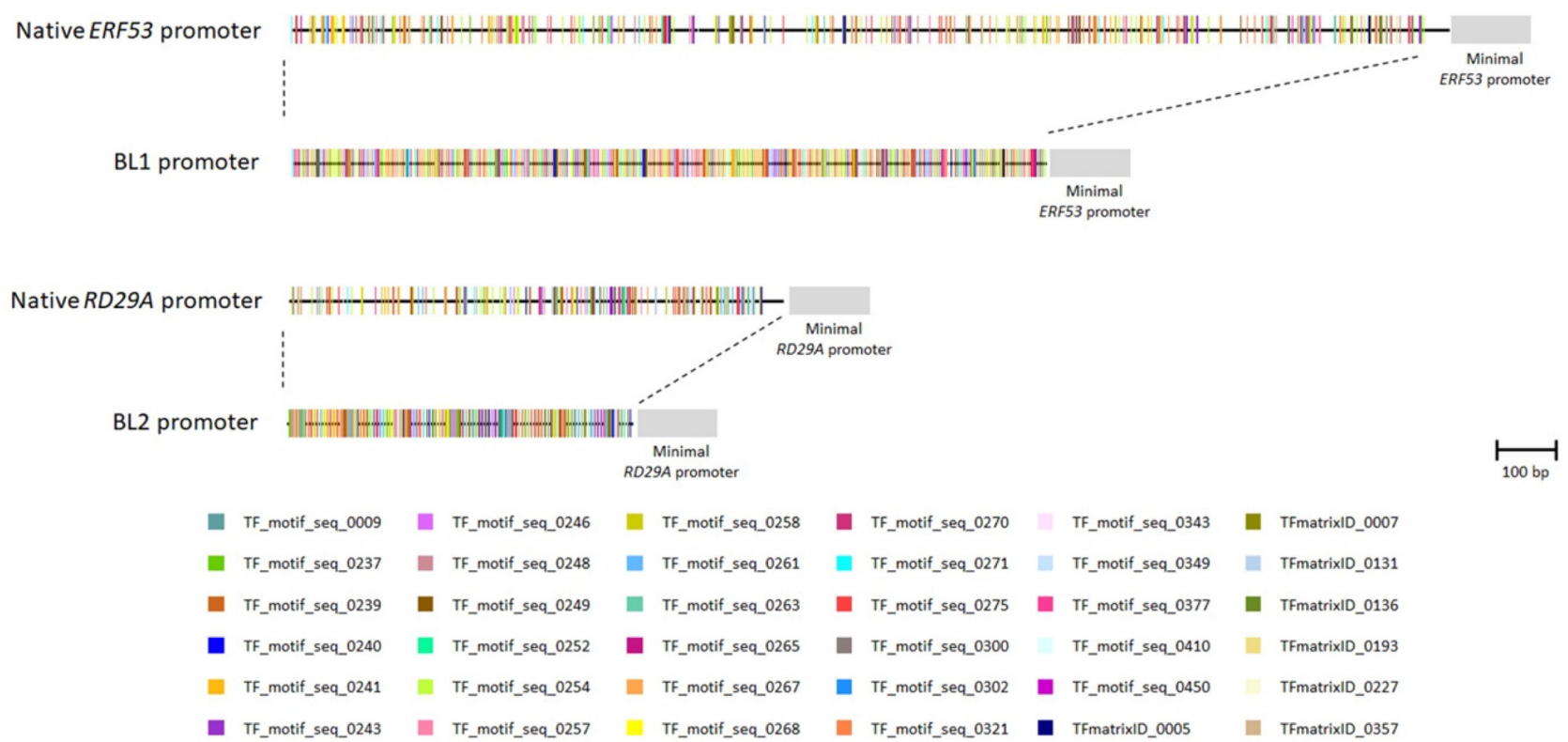

Fig. 3 Design strategy of the synthetic promoters. Different TF-matrix-ID are marked with different color rectangles and approximately placed according to their actual position on the promoter. Rectangles indicated the forward strand of DNA

지로 옮겨 가뭄 스트레스를 해소한 애기장대 잎의 P5CS1 (At2g39800), LTI30 (At3g50970), ATHB-7 (At2g46680) 유전 자의 경우에는 $\mathrm{mRNA}$ 의 양이 감소하지 않았으며, $P P 2 C$ (At1g07430), LEA4-5 (At5g06760), ATGOLS2 (At1g56600), EFR53 (At2g20880), RD29A (At5g42310) 유전자의 경우에는 mRNA의 양이 감소하였다(Fig. $1 \mathrm{~A})$. 이와 유사하게 애기장대의 뿌리에서도 같은 결과를 보였다(Fig. $1 \mathrm{~B})$. 이 결과는 $P P 2 C$, LEA4-5, ATGOLS2, ERF53, RD29A 유전자의 경우 가뭄 스트 레스에 의해 발현이 유도되며, 가뭄 스트레스가 해소된 조건에 서는 발현이 억제되는 것으로 보아 각 유전자의 프로모터는 가 뭄 스트레스에 특이적으로 발현이 조절되는 cis-regulatory element를 가질 것으로 생각된다.

\section{가뭄 스트레스에 특이적인 cis-regulatory element 선별 및 합 성프로모터 설계}

RT-PCR을 이용한 가뭄 스트레스에 대한 유전자의 mRNA의 발 현량 변화를 바탕으로 가뭄 스트레스에 특이적인 cis-regulatory element 선별을 위해 각 유전자를 3 개의 그룹으로 나누어 분석 을 진행하였다. PP2C, LEA4-5, ATGOLS2, ERF53, RD29A는 specific-inducible promoter, P5CS1, LTI30, ATHB-7는 continuousinducible promoter, 가뭄 스트레스에 반응하지 않은 유전자는 non-inducible promoter로 분류하였다. 각 그룹에 해당하는 유전 자들의 프로모터 영역의 cis-regulatory element를 분석한 결과, specific-inducible promoter는 42개, Continuous-inducible promoter 는 71개의 공통적인 TF-matrix-ID가 있음을 확인하였다(Fig. $2 \mathrm{~A}, \mathrm{~B})$. 또한, 각 그룹에서 공통적인 TF-matrix-ID와 non-inducible promoter를 분석한 결과에서는 31 개의 공통적인 TF-matrix-ID 가 존재하며, specific-inducible promoter만 가지는 3 개의 TFmatrix-ID, specific-inducible promoter와 continuous-inducible promoter의 공통적인 2개의 TF-matrix-ID가 있음을 확인하였다
(Fig. 2C). 이 결과는 specific-inducible promoter이 가지는 3개 의 TF-matrix-ID는 가뭄 스트레스에 특이적인 요소로 판단되며, specific-inducible promoter와 continuous-inducible promoter의 공통적인 2 개의 TF-matrix-ID는 가뭄 스트레스에 반응하기 위 한 요소로 판단된다. 3 가지 그룹에 공통적인 31개의 TF-matrix$\mathrm{ID}$ 는 프로모터로 작용하기에 최소한의 요소라 생각된다. 상기의 결과를 바탕으로 합성프로모터의 제작을 위해 36개의 TF-matrix$\mathrm{ID}$ 를 선정하였다(Table 3). 합성프로모터의 제작은 가뭄 스트레 스에 의해 발현이 강하게 유도되고, 가뭄 스트레스 해소에 의 해 발현이 빠르게 감소하는 $E R F 53$ 과 $R D 29 A$ 의 프로모터를 이 용하였다(Fig. 1). 특히, ERF53 유전자[16,35,36]와 RD29A 유 전자 $[10,37,38]$ 는 가뭄, 염해 등과 같은 비 생물학적 스트레스 에 의해 발현이 유도되는 결과와 일치한다. 따라서, ERF53 유 전자의 상위 $2 \mathrm{~kb}$ 영역의 프로모터와 $R D 29 A$ 유전자의 상위 $1 \mathrm{~kb}$ 영역의 프로모터에서 각 TF-matrix-ID에 해당하는 cisregulatory element의 서열만 남기고 해당하지 않는 DNA 서열 은 제거하여 각각 $\mathrm{BL} 1$ 및 $\mathrm{BL} 2$ 의 합성프로모터를 설계하였다 (Fig. 3).

\section{가뭄 스트레스에 대한 합성프로모터의 발현 양상과 활성 분석} 합성프로모터에 의해 유도된 $G U S$ 유전자의 발현은 GUS 반응 혼합물에 의해 확인되었다(Fig. 4). 본 실험에서는 음성 대조군 으로 pCB308 (공 벡터)가 형질전환된 식물을 사용하였으며, 양 성 대조군으로는 기존에 스트레스에 의해 유도된다고 잘 알려 진 $R D 29 A$ 프로모터와 GUS 유전자가 연결된 벡터가 형질전환 된 식물을 대표적으로 사용하였다[10,37,38]. RD29A 프로모터 와 GUS 유전자가 연결된 벡터가 형질전환된 식물, BL1 프로 모터 및 BL2 프로모터와 GUS 유전자가 연결된 벡터가 형질전 환된 식물은 가뭄 스트레스에 반응하여 GUS 염색이 증가하였 다. 특히, 정상적인 생육조건 및 스트레스 해소 조건에서 2 개의 


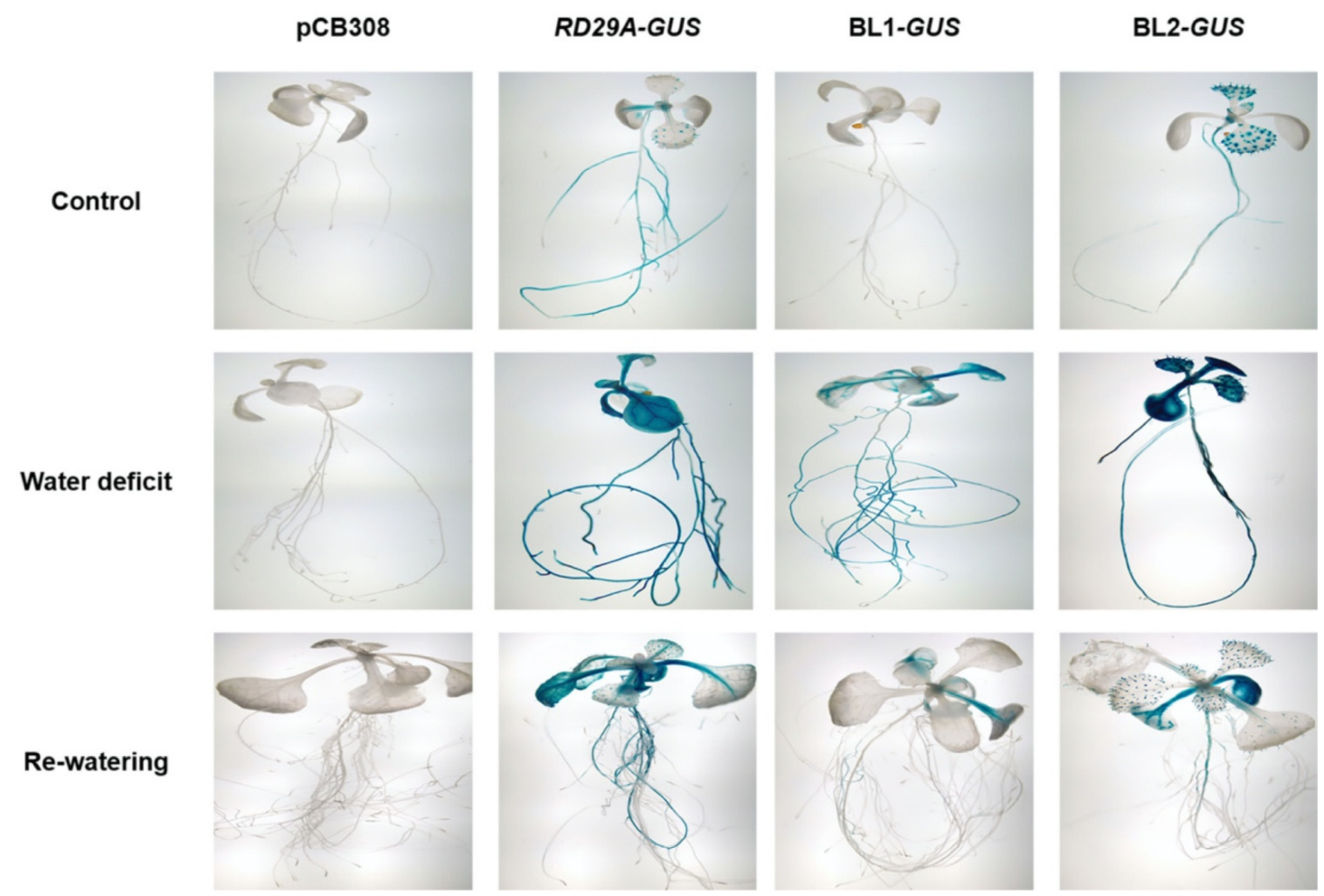

Fig. 4 Histochemical localization of $\beta$-glucuronidase (GUS) activity in transgenic Arabidopsis plants. Arabidopsis plants containing various promoter constructs were grown on 1/2 MS agar for 8 days. After 8 days. The samples were transferred to PEG agar and grown for 3 days. Each of samples was transferred to fresh $1 / 2 \mathrm{MS}$ agar. The transferred transgenic plants were grown during 3 days for re-watering

합성프로모터(BL1, BL2)는 RD29A 프로모터보다 GUS 염색이 적었다. 그러나, 음성 대조군으로 사용된 $\mathrm{pCB} 308$ (공 벡터) 형 질전환 식물은 가뭄 스트레스에 상관없이 염색이 되지 않았다. 합성프로모터의 반응성을 정량적으로 분석하기 위해 GUS 단백 질의 활성을 측정하였다(Fig. 5). 잎에서의 GUS 단백질의 활성 을 측정한 결과 $R D 29 A$ 프로모터, $\mathrm{BL} 1$ 프로모터 및 $\mathrm{BL} 2$ 프로 모터가 형질전환된 식물은 가뭄 스트레스에 의해 GUS 단백질 의 활성이 각각 약 49배, 17 배, 10 배가 증가하였다(Fig. 5A). 이와 유사하게 뿌리에서도 GUS 단백질의 활성이 각각 약 5배, 15배, 6배가 증가함을 확인하였다(Fig. 5B). 그러나, pCB308이 형질전환된 식물은 가뭄 스트레스와 상관없이 잎과 뿌리 모두 에서 GUS 단백질의 활성 차이가 없었다. 특히, 잎과 뿌리에서 $R D 29 A$ 프로모터가 형질전환된 식물의 GUS 단백질의 높은 활 성은 가뭄 스트레스가 해소된 조건에서도 발현되었던 단백질들 이 많이 남아있어 활성이 높은 수준으로 존재하는 것으로 생각 된다. 이런 결과는 Yamaguchi-Shinozaki와 Shinozaki의 연구 [39]로 보고된 $R D 29 A$ 프로모터는 가뭄 스트레스에 반응하여 높 은 수준으로 발현이 유도되어 가뭄 스트레스에 적응 및 대처가 높을 수 있지만, 가뭄 스트레스 상황이 지난 후에도 유도되었 던 단백질의 활성이 남아있어 정상적인 생육 상태로 회복하기 에는 다소 효율적이지 못할 것으로 생각된다. 이에, 2 개의 합성 프로모터(BL1, BL2)는 가뭄 스트레스에 의해 유도되는 발현량 은 낮으나 가뭄 스트레스 상황이 해소되었을 경우, 유도되었던 단백질의 활성이 거의 남아있지 않기 때문에 정상적인 생육 상 태로 효율적으로 회복할 수 있을 것이라 예상되며, turn on 및 off가 가능한 합리적인 프로모터라고 생각된다.

\section{Transient activity assay}

2개의 합성프로모터(BL1, BL2)가 가뭄 스트레스뿐만 아니라 다 른 비 생물학적 스트레스에도 반응하는지 확인하기 위하여 비 생물학적 스트레스 중 추위에 의해 발현이 유도되는 전사조절 인자인 DREB1A [40]와 고온에 의해 발현이 유도되는 전사조 절인자인 DREB2C [41]에 대한 반응성을 조사하였다. 비 생물 학적 스트레스인 추위 및 고온에 의해 유도되는 대표적인 전사 조절인자인 $\mathrm{DREB} 1 \mathrm{~A}$ 와 $\mathrm{DREB} 2 \mathrm{C}$ 에 대한 합성프로모터의 반응 성 확인은 애기장대 잎으로부터 추출한 원형질체를 이용한 transient activity assay를 통해 수행되었다. 추출된 원형질체 내 부로 effector 벡터, reporter 벡터 및 internal control 벡터를 $\mathrm{PEG}$ 를 이용하여 동시에 형질전환 시켰다(Fig. 6A). Effector로 는 $\mathrm{DREB} 1 \mathrm{~A}$ 또는 $\mathrm{DREB} 2 \mathrm{C}$ 전사조절인자를 사용하였고, reporter로는 합성프로모터인 $\mathrm{BL} 1$ 과 $\mathrm{BL} 2$ 프로모터를 $G U S$ 유전 자 앞에 삽입한 것을 사용하였고, internal control로는 NAN 단 백질을 사용하였다. 그 결과 effector 벡터를 넣어 주지 않고 reporter 벡터만 넣어준 대조 구보다 DREB1A 전사조절인자는 positive control로 사용한 $R D 29 A$ 프로모터와 합성프로모터인 $\mathrm{BL} 1$ 프로모터, BL2 프로모터에 각각 약 26배, 3배, 23배 정도 의 GUS 유전자의 발현을 활성화하였다(Fig. $6 \mathrm{~B}$ ). DREB2C 전 사조절인자는 $R D 29 A$ 프로모터와 합성프로모터인 $\mathrm{BL} 1$ 프로모 터, BL2 프로모터에 각각 약 17배, 3 배, 13 배 정도의 GUS 유 전자의 발현을 활성화하였다(Fig. $6 \mathrm{C}$ ). 이 결과는 본 연구에서 
Table 3 List of selected cis-regulatory element

\begin{tabular}{|c|c|c|}
\hline TF-matrix-ID & cis-regulatory element & TF-family \\
\hline TF_motif_seq_0237 & AGATA, AGATG, CGATG, GGATA, GGATG, TGATA, AGATC & GATA;tify \\
\hline TF_motif_seq_0239 & AAAGA, AAAGC, AAAGT, AAGGA, AAGGT & Dof \\
\hline TF_motif_seq_0240 & ACGTC, ACGTT, ACGTA, ACGTG & bZIP \\
\hline TF_motif_seq_0241 & ATTAA, ATTAC, ATTAG, ATTAT & ZF-HD \\
\hline TF_motif_seq_0243 & GATAA, GATAC, GATAG, GATAT & GATA;tify \\
\hline TF_motif_seq_0246 & TGACA, TGACG & Homeodomain;TALE \\
\hline TF_motif_seq_0248 & $\begin{array}{l}\text { AACAG, AACGA, AACTG, AATGG, ACCGG, ATCGG, TACGG, AAAGG, AACGT, } \\
\text { AAGGG, CACGG }\end{array}$ & (Motif sequence only) \\
\hline TF_motif_seq_0249 & AAGTG, ACATG, ACTTG, AGGTG, ATGTG, ACGCG & (Motif sequence only) \\
\hline TF_motif_seq_0252 & GGATT, AGATT & Myb/SANT;MYB;ARR-B \\
\hline TF_motif_seq_0254 & $\begin{array}{l}\text { ATATA, ATCAA, ATCCA, ATCGA, ATCTA, ATCTC, ATCTG, ATCTT, ATGTA, ATTTA, } \\
\text { TTCTA, ACCTA, CTCTA }\end{array}$ & AP2;ERF \\
\hline TF_motif_seq_0257 & $\begin{array}{l}\text { ACAAT, CAAAT, CCAAA, CCAAG, CCAAT, CCATT, CCCAT, CGAAT, CTAAT, GCAAT, } \\
\text { TCAAT, CCAGT, CCTAT }\end{array}$ & NF-YB;NF-YA;NF-YC \\
\hline TF_motif_seq_0258 & ACGAC, CCCAC, CCGAA, CCGAC, CCGTC, CTGAC, CAGAC, TCGAC & Dehydrin \\
\hline TF_motif_seq_0261 & AAGAC, GAAAC, GAGAA, GAGAC, GAGAG, GAGAT & (Motif sequence only) \\
\hline TF_motif_seq_0263 & ACCAC, GCCAA, GCCAT, GCCGC, GCCTC, GGCAC, TCCAC, GACAC, GCCAC & (Motif sequence only) \\
\hline TF_motif_seq_0265 & GGACC, GGGCT, GGGGC, GGTCC, GGGCC, GTGCC & (Motif sequence only) \\
\hline TF_motif_seq_0267 & $\begin{array}{l}\text { GGTAC, GTGAC, GTTAA, GTTAC, GTTAG, GTTAT, GTTCC, GTTGC, GTTTC, CTTAC, } \\
\text { GTAAC, GTCAC }\end{array}$ & Trihelix \\
\hline TF_motif_seq_0268 & TGATT, CGATT & (Motif sequence only) \\
\hline TF_motif_seq_0270 & TGACC, TGACT & WRKY \\
\hline TF_motif_seq_0271 & TGAAG, TGAGG, TGATG, TGCCG, TTACG, AGACG, CGACG & bZIP \\
\hline TF_motif_seq_0275 & $\begin{array}{l}\text { TAGAC, TGGAC, TTCAC, TTGAA, TTGAC, TTGAG, TTGAT, TTGGC, TTGTC, TTTAC, } \\
\text { ATGAC }\end{array}$ & (Motif sequence only) \\
\hline TF_motif_seq_0300 & CACGTC, CACGTT, CACATG, CACGCG, TACGTG & bHLH \\
\hline TF_motif_seq_0302 & CAATTG, CATGTG, CATTTG & bHLH \\
\hline TF_motif_seq_0321 & GAAAAA, GAAAAT, GATAAT, GGAAAA, GATAAA, GGTAAA & (Motif sequence only) \\
\hline TF_motif_seq_0343 & AAACAAA, AAACACA, AAACAAT, AAACAGA & (Motif sequence only) \\
\hline TF_motif_seq_0349 & ACCGACT, ACTGACA, ACAGACA, ACCGACA, GCCGACA & (Others) \\
\hline TF_motif_seq_0377 & TAACAAG, TAACACG, TAACATA, TAACAAA & (Motif sequence only) \\
\hline TF_motif_seq_0410 & $\begin{array}{l}\text { ATAAGTTT, ATACACGT, ATACATTT, ATACGTTA, ATACCTAT, ATACGTGT, } \\
\text { TTACGTAT }\end{array}$ & bHLH \\
\hline TFmatrixID_0131 & $\begin{array}{l}\text { AAAAATAAA, TTGTATAAA, ACGTATAAA, AGGAATAAA, CAGGATAAA, } \\
\text { TAAAATAAA, TATAATAAA }\end{array}$ & AT-Hook \\
\hline TFmatrixID_0136 & AAAATAAA, ATAATAAA & AT-Hook \\
\hline TFmatrixID_0193 & ACACAAGT, ACACGTTA, ACACTTCT, ACATGGGT, ACACGCGT, ACATGAGT & bZIP \\
\hline TFmatrixID_0357 & GGAATATTCT & Myb/SANT;G2-like;MYB \\
\hline TF_motif_seq_0009 & $\begin{array}{l}\text { AAGTCAAAGC, ACATCTTAGT, ACGTCATCTT, ACATCATTCA, ACGACGTAAA, } \\
\text { ACGTCACACC }\end{array}$ & (Motif sequence only) \\
\hline TF_motif_seq_0450 & $\begin{array}{l}\text { TGACGACA, TGACTTGA, TTACGTCG, CGACGTAA, TGACATCA, TGACCACA, } \\
\text { TGACGTCA }\end{array}$ & (Motif sequence only) \\
\hline TFmatrixID_0005 & AAATTAATTA & AT-Hook \\
\hline TFmatrixID_0007 & TAATTAAGTA, AAATTAATTT & AT-Hook \\
\hline TFmatrixID_0227 & CATTTGAAGA, AGTTTGAAAG & TCR;CPP \\
\hline
\end{tabular}

제작한 합성프로모터가 가뭄 스트레스뿐만 아니라 저온 및 고 온에 해당하는 비 생물학적 스트레스에도 발현을 유도할 수 있 으므로, 다양한 비 생물학적 스트레스 환경에 효과적으로 대응 가능할 수 있을 것으로 사료된다. 종합적으로 상기의 결과들로
부터 가뭄 스트레스에 특이적인 cis-regulatory element의 조합 을 통한 합성프로모터는 가뭄 스트레스에 효율적으로 발현이 유 도되는 것으로 판단되며, 추가적인 연구를 진행한다면 기존에 알려진 가뭄 스트레스 관련 cis-regulatory element 외에 새로운 

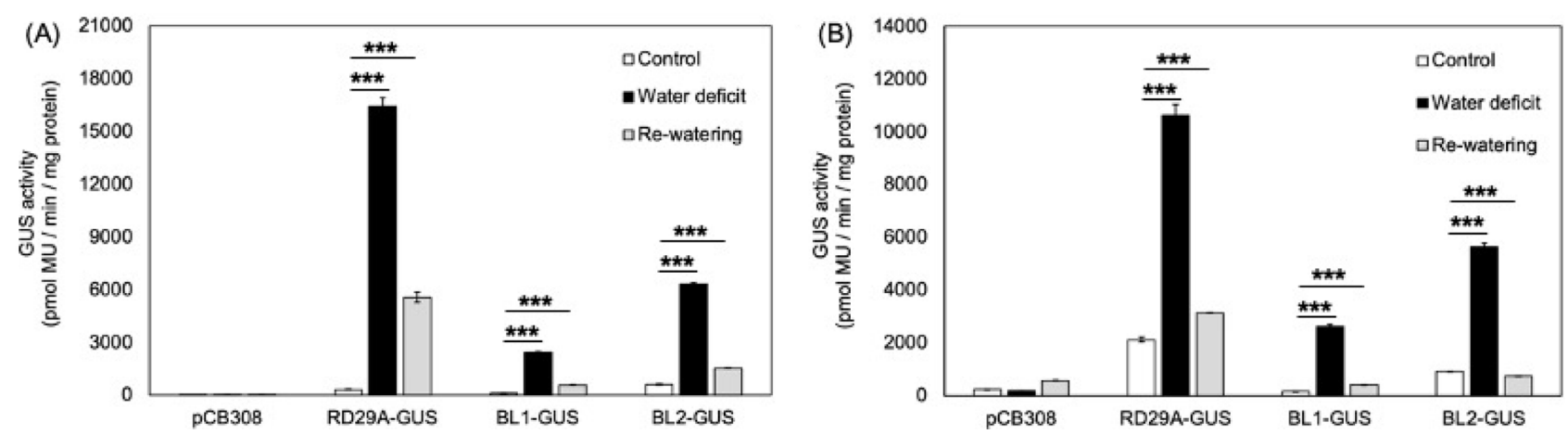

Fig. 5 Comparison of GUS activities of synthetic promoters in transgenic Arabidopsis. Total protein was extracted from the leaves (A) and/or roots (B) of transgenic Arabidopsis plants. The Arabidopsis plants containing various promoter constructs were exposed to water deficit condition. The samples grown on 1/2 MS agar and then transferred to PEG agar. Each of samples was transferred to fresh $1 / 2 \mathrm{MS}$ agar for re-watering. Plant carrying $R D 29 A-$ GUS was used as inducible-expressive control. T2 transformed Arabidopsis plants were sampled to quantify GUS activity. Average GUS activities (pmol product $\min ^{-1} \mathrm{mg}$ protein ${ }^{-1}$ ) were measured in five representative transgenic lines. Values are shown as the mean \pm SD of three independent experiments. $\left({ }^{*} p<0.05,{ }^{* *} p<0.01,{ }^{* * *} p<0.001\right.$, Student's t-test)

(A)

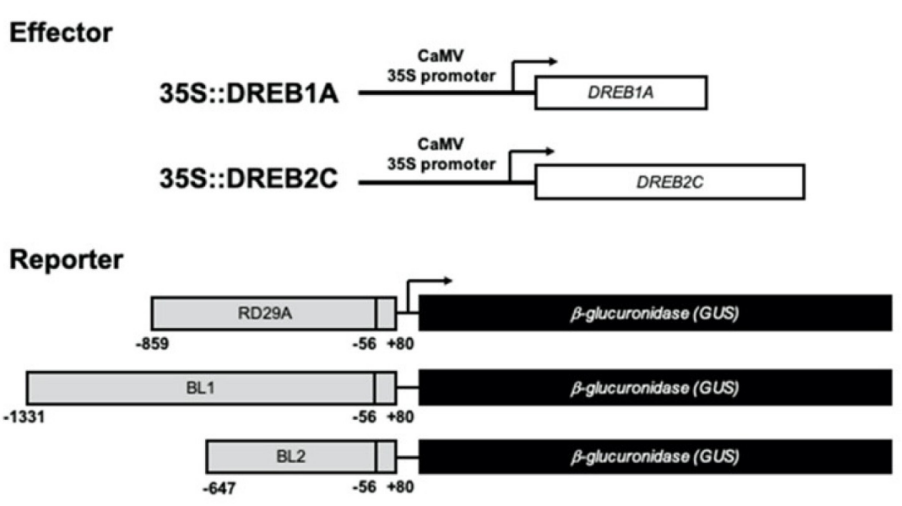

Internal Control

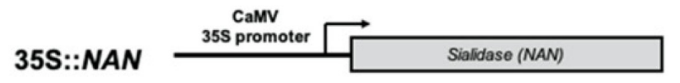

(B)
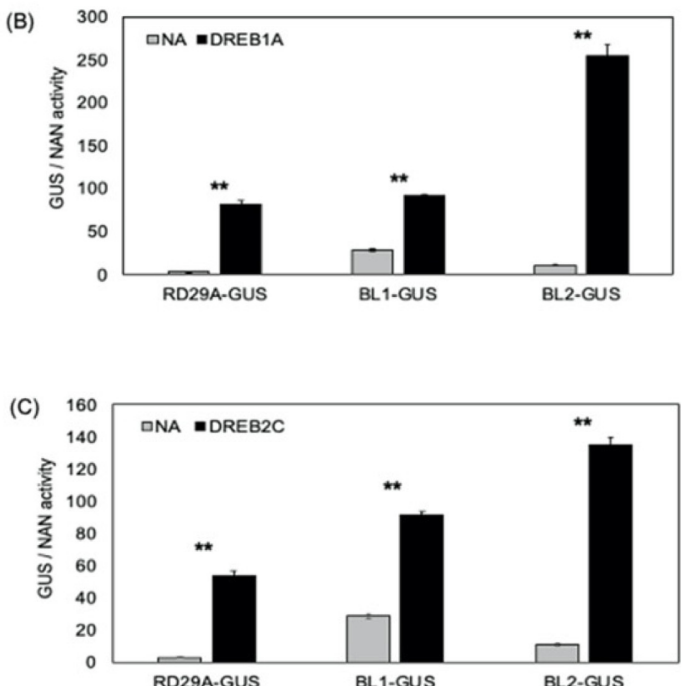

Fig. 6 Analysis of transcriptional activities of synthetic promoters using Arabidopsis protoplasts. Transcription factors were co-expressed in Arabidopsis leaf protoplast with the GUS reporter gene. (A) Diagram of the effector, reporter and internal control constructs used in the transcriptional activation assay. Transcriptional activation analysis showing the effects of the transcription factor on induction of DREB1A (B) and DREB2C (C). NAN activity was used as an internal control. Values are mean $\pm \mathrm{SD}(\mathrm{n}=3) .\left({ }^{*} p<0.05,{ }^{* *} p<0.01\right.$, Student's t-test $)$

cis-regulatory element의 조합을 선별하기 위한 기초 자료로 사 용될 수 있을 것이라 생각된다.

\section{초 록}

가뭄은 작물의 성장과 생산성을 방해하는 비 생물학적 스트레 스 중 하나다. 비 생물학적 스트레스에 대응하기 위해서는 식 물이 불리한 환경 조건에서 스트레스에 나타내는 분자 조절 네 트워크를 이해해야 한다. 비 생물학적 스트레스 (가뭄에 대응) 에 대처할 수 있는 조합을 선별하기 위한 실험에서 스트레스 조건에서만 발현되는 5 개의 가뭄 스트레스 유도성 프로모터를 선별하였으며, 이 중 36개의 cis-regulatory element를 선별하였
다. 그 결과 가뭄 스트레스에서만 발현되는 유전자의 프로모터 에서 cis-regulatory element를 새롭게 조합하여 미세 제어 조절 을 할 수 있는 2 개의 합성프로모터(BL1, BL2)를 제작하였다. 합성프로모터를 포함한 형질전환식물(BL1-GUS, BL2-GUS)의 분석은 합성프로모터가 건조 조건에서 형질전환식물 내의 GUS 유전자의 발현을 증가시키는 것을 통하여 확인하였다. 또한 Transient activation assay를 통해 $\mathrm{DREB} 1 \mathrm{~A}$ 와 $\mathrm{DREB} 2 \mathrm{C}$ 에 의 해 합성프로모터가 활성화되는 것도 확인하였다. 이러한 결과는 가뭄 특이적인 cis-regulatory element의 조합에 의해 제작한 합 성프로모터가 다양한 비 생물학적 스트레스에 반응하고, 식물의 성장 지연을 유발하지 않고 스트레스에 효과적으로 대응할 수 있을 것이라 예상할 수 있다. 
Keywords 가뭄스트레스 · 미세 제어 조절 · 시스 조절 요소 · 합성프로모터

감사의 글 본 논문은 농촌진흥청 차세대 바이오그린 21 사업(세부과제번호: PJ01365701)의 지원에 의해 이루어진 것임

\section{References}

1. Daryanto S, Wang L, Jacinthe PA (2016) Global synthesis of drought effects on maize and wheat production. PLoS One 11(5): e0156362

2. Zhou Y, Tao Y, Zhu J, Miao J, Liu J, Liu Y, Yi C, Yang Z, Gong Z, Liang G (2017) GNS4, a novel allele of DWARF11, regulates grain number and grain size in a high-yield rice variety. Rice 10(1): 1-11

3. Ramakrishna C, Singh S, Raghavendrarao S, Padaria JC, Mohanty S, Sharma TR, Solanke AU (2018) The membrane tethered transcription factor EcbZIP17 from finger millet promotes plant growth and enhances tolerance to abiotic stresses. Sci Rep 8(1): 1-14

4. Yang L, Wu L, Chang W, Li Z, Miao M, Li Y, Yang J, Liu Z, Tan J (2018) Overexpression of the maize E3 ubiquitin ligase gene ZmAIRP4 enhances drought stress tolerance in Arabidopsis. Plant Physiol Biochem 123: $34-42$

5. Kasuga M, Liu Q, Miura S, Yamaguchi-Shinozaki K, Shinozaki K (1999) Improving plant drought, salt, and freezing tolerance by gene transfer of a single stress-inducible transcription factor. Nat Biotechnol 17(3): 287-291

6. Hu H, Dai M, Yao J, Xiao B, Li X, Zhang Q, Xiong L (2006) Overexpressing a NAM, ATAF, and CUC (NAC) transcription factor enhances drought resistance and salt tolerance in rice. PNAS 103(35): 12987-12992

7. Yamaguchi-Shinozaki K, Shinozaki K (2005) Organization of cis-acting regulatory elements in osmotic-and cold-stress-responsive promoters. Trends Plant Sci 10(2): 88-94

8. Hernandez-Garcia CM, Finer JJ (2014) Identification and validation of promoters and cis-acting regulatory elements. Plant Sci 217: 109-119

9. Leavitt JM, Tong A, Tong J, Pattie J, Alper HS (2016) Coordinated transcription factor and promoter engineering to establish strong expression elements in Saccharomyces cerevisiae. Biotechnol J 11(7): 866-876

10. Yamaguchi-Shinozaki K, Shinozaki K (1993) Characterization of the expression of a desiccation-responsive rd29 gene of Arabidopsis thaliana and analysis of its promoter in transgenic plants. Mol Gen Genet 236(23): $331-340$

11. Söderman E, Mattsson J, Engström P (1996) The Arabidopsis homeobox gene ATHB-7 is induced by water deficit and by abscisic acid. Plant J 10(2): $375-381$

12. Savouré A, Hua XJ, Bertauche N, Van Montagu M, Verbruggen N (1997) Abscisic acid-independent and abscisic acid-dependent regulation of proline biosynthesis following cold and osmotic stresses in Arabidopsis thaliana. Mol Gen Genet 254(1): 104-109

13. Taji $T$, Ohsumi $C$, Iuchi $S$, Seki $M$, Kasuga $M$, Kobayashi $M$, Yamaguchi-Shinozaki K, Shinozaki K (2002) Important roles of droughtand cold-inducible genes for galactinol synthase in stress tolerance in Arabidopsis thaliana. Plant J. 29(4) 417-426

14. Hundertmark M, Hincha DK (2008) LEA (late embryogenesis abundant) proteins and their encoding genes in Arabidopsis thaliana. BMC Genomics 9(1): 118

15. Bhaskara GB, Nguyen TT, Verslues PE (2012) Unique drought resistance functions of the highly $\mathrm{ABA}$-induced clade $\mathrm{A}$ protein phosphatase 2Cs. Plant Physiol 160(1): 379-395

16. Hsieh EJ, Cheng MC, Lin TP (2013) Functional characterization of an abiotic stress-inducible transcription factor AtERF53 in Arabidopsis thaliana. Plant Mol Biol 82(3): 223-237
17. Shi H, Chen Y, Qian Y, Chan Z (2015) Low temperature-induced 30 (LTI30) positively regulates drought stress resistance in Arabidopsis: effect on abscisic acid sensitivity and hydrogen peroxide accumulation. Front Plant Sci 6: 893

18. Kim JS, Mizoi J, Yoshida T, Fujita Y, Nakajima J, Ohori T, Todaka D, Nakashima K, Hirayama T, Shinozaki K, Yamaguchi-Shinozaki K (2011) An ABRE promoter sequence is involved in osmotic stressresponsive expression of the DREB2A gene, which encodes a transcription factor regulating drought-inducible genes in Arabidopsis. Plant Cell Physol 52(12): 2136-2146

19. Baker SS, Wilhelm KS, Thomashow MF (1994) The 5'-region of Arabidopsis thaliana cor15a has cis-acting elements that confer cold-, drought-and ABA-regulated gene expression. Plant Mol Biol 24(5): 701-713

20. Kim HJ, Kim YK, Park JY, Kim J (2002) Light signalling mediated by phytochrome plays an important role in cold-induced gene expression through the C-repeat/dehydration responsive element (C/DRE) in Arabidopsis thaliana. Plant Physiol. 29(6): 693-704

21. Abe H, Yamaguchi-Shinozaki K, Urao T, Iwasaki T, Hosokawa D, Shinozaki K (1997) Role of Arabidopsis MYC and MYB homologs in drought-and abscisic acid-regulated gene expression. Plant Cell 9(10): $1859-1868$

22. De Bruxelles GL, Peacock WJ, Dennis ES, Dolferus R (1996) Abscisic acid induces the alcohol dehydrogenase gene in Arabidopsis. Plant Physiol 111(2) 381-391

23. Van der Weele CM, Spollen WG, Sharp RE, Baskin TI (2000) Growth of Arabidopsis thaliana seedlings under water deficit studied by control of water potential in nutrient-agar media. J Exp Bot 51(350): 1555-1562

24. Chang WC, Lee TY, Huang HD, Huang HY, Pan RL (2008) PlantPAN: Plant promoter analysis navigator, for identifying combinatorial cisregulatory elements with distance constraint in plant gene groups. BMC Genomics 9(1): 561

25. Mubeen H, Raza S (2010) In Silico approach to identify transcription factor binding sites and Cis-regulatory elements in tubulin gene promoter. IJSPR 6(5): 31-33

26. Xiang C, Han P, Lutziger I, Wang K, Oliver DJ (1999) A mini binary vector series for plant transformation. Plant Mol Biol 40(4): 711-717

27. Clough SJ, Bent AF (1998) Floral dip: a simplified method for Agrobacterium-mediated transformation of Arabidopsis thaliana. Plant $\mathrm{J}$ 16(6): 735-743

28. Jefferson RA (1988) Plant reporter genes: the GUS gene fusion system. In Genetic engineering (pp. 247-263). Springer, Boston

29. Vitha $S$, Beneš K, Michalova $M$, Ondřej M (1993) Quantitative $\beta$ glucuronidase assay in transgenic plants. Biol Plant 35(1): 151-155

30. Bradford MM (1976) A rapid and sensitive method for the quantitation of microgram quantities of protein utilizing the principle of protein-dye binding. Anal Biochem 72(1-2): 248-254

31. Yoo SD, Cho YH, Sheen J (2007) Arabidops is mesophyll protoplasts: a versatile cell system for transient gene expression analysis. Nat Protoc 2(7): 1565

32. Ko JH, Kim WC, Han KH (2009) Ectopic expression of MYB46 identifies transcriptional regulatory genes involved in secondary wall biosynthesis in Arabidopsis. Plant J. 60(4): 649-665

33. Kim WC, Ko JH, Kim JY, Kim J, Bae HJ, Han KH (2013) MYB 46 directly regulates the gene expression of secondary wall-associated cellulose synthases in Arabidopsis. Plant J 73(1): 26-36

34. Kirby J, Kavanagh TA (2002) NAN fusions: a synthetic sialidase reporter gene as a sensitive and versatile partner for GUS. Plant J 32(3): 391-400

35. Gong W, He K, Covington M, Dinesh-Kumar SP, Snyder M, Harmer SL, Zhu YX, Deng XW (2008) The development of protein microarrays and their applications in DNA-protein and protein-protein interaction analyses of Arabidopsis transcription factors. Mol Plant 1(1): 27-41

36. Cheng MC, Hsieh EJ, Chen JH, Chen HY, Lin TP (2012) Arabidopsis RGLG2, functioning as a RING E3 ligase, interacts with AtERF53 and 
negatively regulates the plant drought stress response. Plant physiol. 158(1): 363-375

37. Kasuga M, Miura S, Shinozaki K, Yamaguchi-Shinozaki K (2004) A combination of the Arabidopsis DREB1A gene and stress-inducible rd29A promoter improved drought-and low-temperature stress tolerance in tobacco by gene transfer. Plant Cell Physiol 45(3): 346-350

38. Msanne J, Lin J, Stone JM, Awada T (2011) Characterization of abiotic stress-responsive Arabidopsis thaliana RD29A and RD29B genes and evaluation of transgenes. Planta 234(1): 97-107

39. Yamaguchi-Shinozaki K, Shinozaki K (1994) A novel cis-acting element in an Arabidopsis gene is involved in responsiveness to drought, low- temperature, or high-salt stress. Plant Cell 6(2): 251-264

40. Maruyama K, Takeda M, Kidokoro S, Yamada K, Sakuma Y, Urano K, Fujita M, Yoshiwara K, Matsukura S, Morishita Y, Sasaki R, Suzuki H, Saito K, Shibata D, Shinozaki K, Yamaguchi-Shinozaki K (2009) Metabolic pathways involved in cold acclimation identified by integrated analysis of metabolites and transcripts regulated by DREB1A and DREB2A. Plant physiol 150(4): 1972-1980

41. Chen H, Hwang JE, Lim CJ, Kim DY, Lee SY, Lim CO (2010) Arabidopsis DREB2C functions as a transcriptional activator of HsfA3 during the heat stress response. Biochem. Biophys Res Commun. 401(2): 238-244 